\title{
TITLE: ARE OPIOIDS INDICATED IN PEDIATRIC STRABISMUS SURGERY?
}

Kimmo Murto FRCPC*, Khalid Chowdary FCPS*, Ibrahim Abushahwan MD*, Greg Bryson FRCPC Nick Barrowman $\mathrm{PhD}^{\S}$ and William Splinter FRCPC*.

"Department of Anesthesiology, Children' Hospital of Eastern Ontario 401 Smyth Rd. Ottawa Ontario K1H 8L1. ${ }^{\S}$ Chalmer's Research Group, CHEO Research Institute, 401 Smyth Rd. Ottawa, Ontario K1H 8L1. ${ }^{\mathfrak{E}}$ Department of Anesthesiology, The Ottawa Hospital, 1053 Carling Ave. Ottawa Ontario K1Y 4E9

INTRODUCTION: The use of intraoperative opioids during strabismus surgery has been associated with increased morbidity. We hypothesized that the administration of opioids during strabismus surgery would produce a smoother postoperative recovery with minimal side effects.

METHODS: With ethics committee approval, 259 consecutive patient's charts were reviewed who underwent elective strabismus surgery under general anesthesia during a 12-month period starting April 2002. The data recorded included patient demographics, method of anesthesia, use of intraoperative opioids, perioperative complications, need for postoperative rescue analgesia and antiemetics and time of discharge. All data are described as proportions or mean +/- SD. Chi-square and unpaired student $t$-tests were applied where appropriate

RESULTS: All 259 children were assessed. The groups had similar demographic data. Forty-eight children received fentanyl, 24 received morphine and one received remifentanil intraoperatively. The proportion of patients requiring at least one postoperative intervention (e.g. administer medications or manage laryngospasm) was somewhat less in those receiving intraoperative narcotics (71\%) than those without $(82 \%)$ although this trend did not reach statistical significance $(\mathrm{P}=0.063)$. There was no difference in the incidence of complications or duration of postoperative stay (see Table1).

Table 1

\begin{tabular}{|c|c|c|c|}
\hline Characteristic & $\begin{array}{c}\text { Intraoperative } \\
\text { Narcotic }\end{array}$ & $\begin{array}{c}\text { No Intraoperative } \\
\text { Narcotic }\end{array}$ & P value \\
\hline $\mathrm{N}(\%)$ & $73(28)$ & $186(72)$ & 0.826 \\
\hline $\begin{array}{c}\text { Intra/postoperative } \\
\text { Complications }\end{array}$ & $7(2.8)$ & $16(6.3)$ & 0.063 \\
\hline $\begin{array}{c}\text { Postoperative } \\
\text { intervention }\end{array}$ & $52(71)$ & $152(82)$ & 0.755 \\
\hline $\begin{array}{c}\text { Duration of } \\
\text { Postoperative Stay } \\
\text { (min) }\end{array}$ & $132 \pm 31$ & $129 \pm 75$ & \\
\hline
\end{tabular}

DISCUSSION: The administration of intraoperative opioids for children undergoing strabismus surgery did not negatively impact on their in-hospital stay. The routine administration of potent antiemetic combinations such as ondansetron plus decadron in our institution are likely responsible for limiting opioid induced nausea and vomiting. The addition of opioids in this population may aid in the differentiation between postoperative pain versus emergence agitation. A prospective randomized controlled double-blind trial is required to accurately document reduced rescue analgesia/ antiemetic requirements and emergence agitation in the 24 hours following surgery before considering the widespread use of opioids in this population. 